University of Nebraska - Lincoln

DigitalCommons@University of Nebraska - Lincoln

Liangcheng Du Publications

Published Research - Department of Chemistry

January 2008

\title{
Fumonisin level in corn-based food and feed from Linxian County, a high-risk area for esophageal cancer in China
}

Jiansheng Wang

Zhejiang University, The State Agriculture Ministry Laboratory of Horticultural, Plant Growth Development and Biotechnology, Hangzhou, China

Ying Zhou

Zhejiang University, The State Agriculture Ministry Laboratory of Horticultural, Plant Growth Development and Biotechnology, Hangzhou, China

Wanbo Liu

University of Nebraska - Lincoln

Xiangcheng Zhu

University of Nebraska - Lincoln

Liangcheng Du

University of Nebraska - Lincoln, Idu3@unl.edu

See next page for additional authors

Follow this and additional works at: https://digitalcommons.unl.edu/chemistrydu

Part of the Chemistry Commons

Wang, Jiansheng; Zhou, Ying; Liu, Wanbo; Zhu, Xiangcheng; Du, Liangcheng ; and Wang, Qiaomei, "Fumonisin level in corn-based food and feed from Linxian County, a high-risk area for esophageal cancer in China" (2008). Liangcheng Du Publications. 9.

https://digitalcommons.unl.edu/chemistrydu/9

This Article is brought to you for free and open access by the Published Research - Department of Chemistry at DigitalCommons@University of Nebraska - Lincoln. It has been accepted for inclusion in Liangcheng Du Publications by an authorized administrator of DigitalCommons@University of Nebraska - Lincoln. 


\section{Authors}

Jiansheng Wang, Ying Zhou, Wanbo Liu, Xiangcheng Zhu, Liangcheng Du, and Qiaomei Wang 
Published in Food Chemistry 106:1 (January 1, 2008), pp. 241-246; doi:10.1016/j.foodchem.2007.05.076

Copyright (C) 2007 Elsevier Ltd. Used by permission. http://www.sciencedirect.com/science/journal/03088146

Submitted January 21, 2007; revised March 28, 2007; accepted May 30, 2007; published online June 7, 2007.

\title{
Fumonisin level in corn-based food and feed from Linxian County, a high-risk area for esophageal cancer in China
}

\author{
Jiansheng Wang ${ }^{\mathrm{a}}$, Ying Zhou ${ }^{\mathrm{a}}$, Wanbo Liu ${ }^{\mathrm{b}}$, Xiangcheng Zhu ${ }^{\mathrm{b}}$, \\ Liangcheng $\mathrm{Du}^{\mathrm{b}}$, and Qiaomei Wang ${ }^{\mathrm{a}, *}$ \\ ${ }^{\text {a }}$ Department of Horticulture, Zhejiang University, The State Agriculture Ministry Laboratory of Horticultural, \\ Plant Growth Development and Biotechnology, Hangzhou 310029, China \\ ${ }^{\mathrm{b}}$ Department of Chemistry, University of Nebraska-Lincoln, Lincoln, NE 68588-0304, USA \\ * Corresponding author — tel: 86571 85909333; fax: 86571 87420554; email: qmwang@zju.edu.cn
}

\begin{abstract}
The level of mycotoxin fumonisins in corn-based food and feed collected from Linxian County, a high-risk area for esophageal cancer in China, has been analyzed using high-performance liquid chromatographic coupled with evaporative laser scattering detector (HPLC-ELSD). A total of 104 corn kernel samples were obtained from local households, granaries, wholesale markets (central markets), and retail markets (stores and supermarkets). Fumonisin $\mathrm{B}_{1}\left(\mathrm{FB}_{1}\right)$ was detected in the samples from households, granaries, central markets, and stores, with a positive rate of $61.5 \%, 50 \%, 33.3 \%$, and $17 \%$, respectively. No fumonisin was detected in samples from the supermarket. The highest $\mathrm{FB}_{1}$ levels $(0.30-3.20 \mu \mathrm{g} /$ $\mathrm{g}$; mean, $1.42 \mu \mathrm{g} / \mathrm{g})$ were found in samples from the granary, followed by household $(0.25-1.80 \mu \mathrm{g} / \mathrm{g} ; \mathrm{mean}, 0.73 \mu \mathrm{g} / \mathrm{g})$, central market $(0.25-1.10 \mu \mathrm{g} / \mathrm{g}$; mean, $0.51 \mu \mathrm{g} / \mathrm{g})$, and store $(0.22-0.34 \mu \mathrm{g} / \mathrm{g}$; mean, $0.28 \mu \mathrm{g} / \mathrm{g})$. Among the 80 corn kernel samples collected from local households, 18 of 24 (75.0\%) moldy samples contained high levels of FB $1(0.28-3.30 \mu \mathrm{g} /$ g; mean, $1.58 \mu \mathrm{g} / \mathrm{g})$, and 20 of $56(35.7 \%)$ apparently healthy samples contained low levels of $\mathrm{FB}_{1}(0.21-0.82 \mu \mathrm{g} / \mathrm{g}$; mean, $0.46 \mu \mathrm{g} / \mathrm{g})$. As the central market plays an important role in trade of corn-based food and feed in China, a total of $115 \mathrm{corn}-$ based food and feed samples were collected from the local central market. The highest $\mathrm{FB}_{1}$ levels $(0.30-3.13 \mu \mathrm{g} / \mathrm{g}$; mean, $1.50 \mu \mathrm{g} / \mathrm{g})$ were found in feed, followed by unprocessed food $(0.31-0.63 \mu \mathrm{g} / \mathrm{g}$; mean, $0.47 \mu \mathrm{g} / \mathrm{g})$ and processed food $(0.21-$ $0.28 \mu \mathrm{g} / \mathrm{g}$; mean, $0.25 \mu \mathrm{g} / \mathrm{g}$ ). The positive incidence of $\mathrm{FB}_{1}$ in feed, unprocessed, and processed food were $53.6 \%, 33.3 \%$ and $17.9 \%$, respectively. In conclusion, the results showed that corn-based food and feed from Linxian County contained low level of $\mathrm{FB}_{1}(<2 \mu \mathrm{g} / \mathrm{g})$ in general, but efforts should be made to control the fumonisin contamination in corn kernels stored in granaries and households.
\end{abstract}

Keywords: Fumonisins, HPLC-ELSD, Corn products

\section{Introduction}

Fumonisins are a class of mycotoxins produced mainly by Fusarium moniliforme (synonym F. verticillioides), a primary fungal contaminant of corn and corn-derived products throughout the world. So far, twenty eight fumonisin analogs have been characterized (Rheeder, Marasas, \& Vismer, 2002). They are classified into four main groups, the A, B, C, and $\mathrm{P}$-series fumonisins. The B-series fumonisins are the most abundant analogs produced by $F$. moniliforme strains, with fu- monisin $\mathrm{B}_{1}\left(\mathrm{FB}_{1}\right)$ being the most abundant and toxic constituent. $\mathrm{FB}_{1}$ accounts for approximately $70 \%$ of total fumonisins found in nature ([Marasas, 2001] and [Nelson et al., 1993]).

Elevated fumonisin level in corn has become an area of concern since ingestion of fumonisin-contaminated corn has been associated with livestock loss and human health risks. Fumonisins were reported to cause leukoencephalomalacia (ELEM) in horses (Marasas, 2001), pulmonary oedema syndrome (PES) in pigs (Harrison, Colvin, Greene, Newman, \& Cole, 1990), and hepatocarcinoma in rats (Gelderblom, Abel, 
\& Smuts, 2001). In addition to the diseases in livestock, consumption of corn-based food contaminated with fumonisins is known to epidemiologically relate to human esophageal cancer (HEC) in people from the Transkei region of South Africa and the Linxian region of China ([Chu and Li, 1994], [Rheeder et al., 1992] and [Sydenham et al., 1990]). It was also reported that gestational exposure to fumonisins may result in birth defects, such as neural tube defects (Hendricks, 1999). Several modes of action have been postulated to explain fumonisin-induced toxicity, but the primary hypothesis involves disruption of de novo sphingolipid biosynthesis (Merrill, Sullards, Voss, \& Riley, 2001). Fumonisins are specific inhibitors of sphinganine $N$-acyltransferase (ceramide synthase), a key enzyme in the biosynthesis of sphingolipids.

The major high-risk areas for HEC in China are located in Henan and Hebei Provinces, with Linxian County in the Henan Province being the highest-risk area. Several surveys have been conducted concerning the natural occurrence of fumonisin in corn samples collected from households in Linxian County. Chu and $\mathrm{Li}$ (1994) detected high level of $\mathrm{FB}_{1}$ (18$155 \mu \mathrm{g} / \mathrm{g}$; mean, $74 \mu \mathrm{g} / \mathrm{g}$ ) in all moldy samples from households in Linxian County, and relatively lower level of $\mathrm{FB}_{1}$ (20-60 $\mu \mathrm{g} / \mathrm{g}$; mean, $35.3 \mu \mathrm{g} / \mathrm{g}$ ) in all normal samples from the same households. However, lower incidence and level of $\mathrm{FB}_{1}$ were also reported in other surveys conducted in Linxian County by (Yoshizawa et al., 1994) and (Wang and Zhu, 2002). The content of $\mathrm{FB}_{1}$ varied greatly among different surveys conducted in Linxian County, which may be due to the different methods used for fumonisin analysis. As reported recently (Shephard, Van der Westhuizen, Gatyeni, Katerere, \& Marasas, 2005), fumonisins detected in food using indirect analytical methods could sometimes produce false positive results, and it is important to have more definitive techniques to validate the results, because Linxian County is a main cornproducing and HEC-high-risk area in China.

Moreover, corns produced by farmers in Linxian County are not only stored and consumed by themselves in household, but also stored in granary or traded in local wholesale and retail markets. The trade of corn-based foods and feeds has been increasing in the local markets. However, limited information is available on fumonisin contamination in corn-based foods and feeds traded in Linxian County. It is important to investigate fumonisin contamination in various sources. The objective of this work was to use HPLC-ELSD to directly identify and measure fumonisins in corn and corn-based food and feed from different sources in Linxian County.

\section{Materials and methods}

\subsection{Chemicals}

High-performance liquid chromatography (HPLC)-grade acetonitrile was from EM Science (Darmstadt, Germany) or from Fisher Scientific (Pittsburgh, PA). Standard $\mathrm{FB}_{1}, \mathrm{FB}_{2}$,
$\mathrm{FB}_{3}$, and $\mathrm{FB}_{4}$ were gifts from Ronald D. Plattner (US Department of Agriculture [USDA], Peoria, Ill.).

\subsection{Sample collection}

Corn kernel samples were collected from local farmers (household), granaries, central markets, stores, and supermarkets, while unprocessed corn kernels, processed corn foods, and corn-based feed were taken from local central market in Linxian County, Henan Province, in the period from July 2005 to May 2006. The processed corn foods included corn grit, corn flour, corn meal, corn tortilla chips and vacuumpackaging cooked corn. The samples were sent to the laboratory as soon as they were collected, and tested upon arrival or stored at $-20^{\circ} \mathrm{C}$ to arrest any fumonisin formation up to the time of analysis.

\subsection{Determination of fumonisin}

Analysis of fumonisins was performed according to our former method (Bojja, Cerny, Proctor, \& Du, 2004), with minor modifications.

\subsubsection{Extraction and clean up}

A $10 \mathrm{~g}$ aliquot of the sample was placed in a flask containing $25 \mathrm{ml}$ acetonitrile/water $(1: 1, \mathrm{v} / \mathrm{v})$. Samples were placed in an orbital shaker overnight, filtered and a 10-ml aliquot was transferred to a $50 \mathrm{ml}$ centrifugal tube and added $40 \mathrm{ml}$ deionized water. Clean up of the extract was performed in $300 \mathrm{mg}$ Amberlite XAD-4, previously conditioned with $2 \mathrm{ml}$ of methanol and $20 \mathrm{ml}$ of deionized water. After the initial washing with $200 \mathrm{ml}$ deionized water, the extract was eluted with $3 \mathrm{ml}$ $100 \%$ methanol. The eluent was dried under vacuum with freezing at $-65^{\circ} \mathrm{C}$ and stored at $-20{ }^{\circ} \mathrm{C}$, up to the moment of quantification.

\subsubsection{Chromatographic quantification of fumonisins by HPLC-ELSD analysis}

Samples were dissolved in $200 \mu \mathrm{l}$ water and filtered through a $0.2 \mu \mathrm{m}$ syringe-filter. A $20 \mu \mathrm{l}$ aliquot was injected directly into the HPLC-ELSD system and used for quantification of the fumonisins. The HPLC system was a ProStar, Model 210 (Varian Walnut Creek, CA) with a column of Alltima C18LL, $5 \mu \mathrm{m}, 250 \times 4.6 \mathrm{~mm}$ inner diameter (Alltech, Deerfield, Ill.). The HPLC-ELSD method conditions were performed according to our previous studies with some modifications (Bojja et al., 2004). The mobile phases were (A) water-TFA (100:0.025, v/v) and (B) acetonitrile-TFA 100:0.025, $(\mathrm{v} / \mathrm{v})$, with a gradient of $0-20 \% \mathrm{~B}$ in $\mathrm{A}$ in the first $5 \mathrm{~min}$, $20-40 \%$ B from 5 to $10 \mathrm{~min}, 40-80 \%$ B from 10 to $15 \mathrm{~min}$, $80 \%$ B from 15 to $20 \mathrm{~min}$, and $80-0 \%$ B from 20 to $25 \mathrm{~min}$. The flow rate was $1.0 \mathrm{ml} / \mathrm{min}$. The conditions set for ELSD (ELSD 2000, Alltech, USA) were $45^{\circ} \mathrm{C}$ of drift tube temperature, $2.0-1 / \mathrm{min}$ nitrogen gas flow, and gain value of 1 in the impactor-on mode. 
In quantitative analyses, a volume of $20 \mu \mathrm{l}$ standard $\mathrm{FB}_{2}$ $\mathrm{FB}_{3}$ and $\mathrm{FB}_{4}$ samples $(1 \mu \mathrm{g} / \mu \mathrm{l})$ was injected for HPLC-ELSD analysis, and standard $\mathrm{FB}_{1}(10 \mu \mathrm{g} / \mu \mathrm{l})$ was diluted in four different concentrations of $0.15,0.3,0.6,1.2 \mu \mathrm{g} / \mu \mathrm{l}$ with the same method above. The peak area from the responding peak was integrated using on-system tools provided by Varian. At least 2 injections were made for each concentration, and the peak areas were then plotted against the absolute amounts of $\mathrm{FB}_{1}$ used to obtain a standard curve. Under the established conditions, standard $\mathrm{FB}_{1}$ gave a peak at a retention time of 16.26 min. Retention times for standard $\mathrm{FB}_{3}, \mathrm{FB}_{2}$ and $\mathrm{FB}_{4}$ were $16.9,17.2$, and $17.9 \mathrm{~min}$, respectively.

The method gave a linear response in the range of 3$24 \mu \mathrm{g} \mathrm{FB}_{1}$ with $R^{2}=0.9828$. In five independent spiking experiments, where a known amount of standard $\mathrm{FB}_{1}$ was added to the food sample, the recovery rate was also determined. The rates varied from $88.6 \%$ to $112.7 \%$, with an average of $102.6 \%$ and a standard deviation of $8.9 \%(n=5)$. The limit of determination was $3 \mathrm{ng} / \mu \mathrm{l}$ for FBs.

\section{Results and discussion}

Linxian County is one of the main maize-producing areas in Henan Province. Corn produced in Linxian County is either stored by local farmers and in granaries, or traded in local markets. The newly harvested corn cobs without husk, are usually dried under the sun on the ground floor in order to reduce the moisture content; then the sufficiently dried cobs are shelled, and the corn kernels are either stored or traded. Local farmers usually store the corn kernels in gunnysacks or put them in cement tanks inside the house without any ventilated equipment, for household storage. As for granary storage, no ventilated equipment is used either. The corn kernels are stored in cement tanks after wrapped with plastic film, and the top of cement tanks are then covered with straw mat to avoid insect and rodent attack. The newly harvested corn kernels with good visual quality and low moisture content, are usually traded in the markets. In all the corn samples analyzed, $\mathrm{FB}_{1}$ was the only fumonisin detected, and no detectable levels of $\mathrm{FB}_{2}, \mathrm{FB}_{3}$ and $\mathrm{FB}_{4}$ were found. In previous studies, the co-occurrence of $\mathrm{FB}_{1}$ and $\mathrm{FB}_{2}$ in corn (Yoshizawa et al., 1994), corn-based food (Bittencourt, Oliveira, Dilkin, \& Corrêa, 2005), and feed (Sanchis et al., 1995), with $\mathrm{FB}_{1}$ being the predominant fumonisin have been reported. In our test, only $\mathrm{FB}_{1}$ was detectable in corn samples, which agrees with some other surveys in Linxian County ([Chu and Li, 1994], [Wang et al., 2000] and [Wang and Zhu, 2002]).

We collected a total of 104 corn kernel samples from local households, granaries, central markets, stores and supermarkets for fumonisin analysis. The highest incidence of $\mathrm{FB}_{1}$ contamination $(61.5 \%)$ was found in samples from households, followed by from granaries $(50 \%)$, central markets $(33.3 \%)$, and stores $(17.0 \%)$. No $\mathrm{FB}_{1}$ was detected in samples from supermarkets. The highest $\mathrm{FB}_{1}$ level $(0.30-3.20 \mu \mathrm{g} /$ $\mathrm{g}$; mean, $1.42 \mu \mathrm{g} / \mathrm{g}$ ) was found in samples from granaries, followed by households $(0.25-1.80 \mu \mathrm{g} / \mathrm{g}$; mean, $0.73 \mu \mathrm{g} / \mathrm{g})$, central markets $(0.25-1.10 \mu \mathrm{g} / \mathrm{g}$; mean, $0.51 \mu \mathrm{g} / \mathrm{g})$, and stores $(0.22-0.34 \mu \mathrm{g} / \mathrm{g} ;$ mean, $0.28 \mu \mathrm{g} / \mathrm{g}$ ) (Table 1).

No moldy corn kernel samples were found in the central and retail markets during our sampling, and all the samples collected were apparently healthy corn without any visible mold contamination, which may explain the low incidence and levels of $\mathrm{FB}_{1}$ in corn samples traded in the markets in the present survey. As most of the moldy samples were from households, we conducted another survey, randomly collecting 80 samples from household and dividing them into two groups, moldy and normal healthy, according to their surface character. $\mathrm{FB}_{1}$ analysis of the samples showed that high levels of $\mathrm{FB}_{1}$ (from 0.28 to $3.30 \mu \mathrm{g} / \mathrm{g}$; mean, $1.58 \mu \mathrm{g} / \mathrm{g}$ ) were found in 18 of $24(75 \%)$ moldy samples, while low levels (from 0.21 to $0.82 \mu \mathrm{g} / \mathrm{g}$; mean, $0.46 \mu \mathrm{g} / \mathrm{g}$ ) were found in 20 of $56(35.7 \%)$ apparently healthy samples (Table 2), which suggested that even corn samples with normal surface character might contain fumonisin.

Our results indicated that fumonisin levels of all samples were significantly lower compared to the maximum level of FDA listed (2-4 ppm for human food) (FDA, 2002). Specifically, the samples from supermarket were free of $\mathrm{FB}_{1}$ contamination, although $\mathrm{FB}_{1}$ contamination was slightly more serious in corn kernel samples from local households and granaries than those from local markets. Several previous surveys have been conducted concerning the natural occurrence of

Table 1. Fumonisin contamination of corn from different sources

\begin{tabular}{|c|c|c|c|c|c|}
\hline \multirow[t]{2}{*}{ Source } & \multicolumn{3}{|c|}{ Samples } & \multicolumn{2}{|c|}{$\begin{array}{l}\text { Level of } \mathrm{FB}_{1} \text { in positive } \\
\text { samples }\end{array}$} \\
\hline & Nun & & Positive (incidence) & Mean $(\mu \mathrm{g} / \mathrm{g})$ & Range $(\mu \mathrm{g} / \mathrm{g})$ \\
\hline \multicolumn{2}{|c|}{ Household } & $2 \theta$ & $16(61.5 \%)$ & $0.73 \pm 0.18^{1}$ & $0.25-1.80$ \\
\hline \multicolumn{2}{|c|}{ Granary } & 24 & $12(50.0 \%)$ & $1.42 \pm 1.51$ & $0.30-3.20$ \\
\hline \multicolumn{2}{|c|}{ Central market } & 36 & $12(33.3 \%)$ & $0.51 \pm 0.28$ & $0.25-1.10$ \\
\hline \multicolumn{2}{|c|}{ Store } & 12 & $2(17.0 \%)$ & $0.28 \pm 0.08$ & $0.22-0.34$ \\
\hline \multicolumn{2}{|c|}{ Supermarket } & 6 & 0 & -2 & - \\
\hline
\end{tabular}

${ }^{1}$ Mean \pm standard derivation.

${ }^{2}$ Below detection limit.

Table 2. Fumonisin contamination of corn samples from household

\begin{tabular}{|c|c|c|c|c|c|}
\hline \multirow[t]{2}{*}{$\begin{array}{l}\text { Surface } \\
\text { character }\end{array}$} & \multicolumn{3}{|c|}{ Samples } & \multicolumn{2}{|c|}{$\begin{array}{l}\text { Level of } F_{B_{1}} \text { in positive } \\
\text { samples }\end{array}$} \\
\hline & Numbe & Pos & ve (incidence) & Mean $(\mu \mathrm{g} / \mathrm{g})$ & Range $(\mu \mathrm{g} / \mathrm{g})$ \\
\hline \multirow{2}{*}{\multicolumn{2}{|c|}{$\begin{array}{l}\text { Moldy samples } \\
\text { Normal samples }\end{array}$}} & 24 & $18(75.0 \%)$ & $1.58 \pm 1.21$ & $0.28-3.30$ \\
\hline & & 56 & $20(35.7 \%)$ & $0.46 \pm 0.20$ & $0.21-0.82$ \\
\hline
\end{tabular}


fumonisin in corn samples collected from households in Linxian County. Chu and $\mathrm{Li}$ (1994) detected high level of $\mathrm{FB}_{1}$ in concentrations ranging from 18 to $155 \mu \mathrm{g} / \mathrm{g}$ (mean $74 \mu \mathrm{g} / \mathrm{g}$ ) in all moldy samples from households in Linxian County, and relatively lower level of $\mathrm{FB}_{1}$ in concentrations ranging from 20 to $60 \mu \mathrm{g} / \mathrm{g}$ (mean $35.3 \mu \mathrm{g} / \mathrm{g}$ ) was detected in all normal samples from the same households. However, lower incidence and level of $\mathrm{FB}_{1}$ were also reported in another survey conducted in Linxian County by Yoshizawa and his colleagues, who described $\mathrm{FB}_{1}$ contamination frequencies of $48 \%$ with average $\mathrm{FB}_{1}$ level of $0.872 \mu \mathrm{g} / \mathrm{g}$ (Yoshizawa et al., 1994). A recent report by Wang and $\mathrm{Zhu}$ (2002) showed that $\mathrm{FB}_{1}$ at the concentrations ranging from 1.07 to $2.56 \mu \mathrm{g} / \mathrm{g}$ was detected in $50 \%$ of moldy corn samples collected from households of Jingtou village in Linxian County, while low level $(0.21-0.737 \mu \mathrm{g} / \mathrm{g})$ of $\mathrm{FB}_{1}$ was detected in $10.5 \%$ of 19 normal samples from the same households. Both the incidence and level of $\mathrm{FB}_{1}$ in either moldy or healthy corn samples from household in Linxian County in the current survey were much lower than those reported by Chu and $\mathrm{Li}$ (1994), but similar to those reported by (Wang and Zhu, 2002) and (Wang and Zhu, 2002).

The variation of $\mathrm{FB}_{1}$ content among different surveys in corn from households in Linxian County may be related to the climate conditions during and after harvest. For example, harvest occurring during a rainy period favours for fungal growth and fumonisin production (Jackson \& Jalonski, 2004). Our results indicate, that although some helpful means have been adopted to control the fumonisin contamination of corn from household in Lianxian County in recent years, there are still many areas requiring improvements. For example, moldy corn is still harvested, stored, and consumed by the rural population in Linxian County, which represents a health risk for the people.

A direct detection method was used to determine the level of fumonisin contaminations in corn from granaries and markets in Linxian County. The results suggested that both the incidence and level of $\mathrm{FB}_{1}$ in corn samples from granaries were higher than those of markets, with $\mathrm{FB}_{1}$ level as high as $3.20 \mu \mathrm{g} / \mathrm{g}$ being determined. Although fumosinsin formation is believed to occur predominately in corn before harvest, it was also reported that the toxins could be formed during post-harvest storage, especially when corn was inadequately stored at high temperature and high relative moisture (Jackson \& Jalonski, 2004). The relatively heavy $\mathrm{FB}_{1}$ contamination in corn from granary might be related to the storage environment and method. It is easy to create partial high moisture in corn stored in such a non-ventilated storage system as granary, which is suitable for fungal (Fusarium) growth and mycotoxin production. A simple and effective method to reduce fumonisin contamination is to keep corn kernels sufficiently dried (moisture content less than 13\%) before storage to ensure unfavourable conditions for fungal growth. To do this, the corn cob without husk can either be dried on the floor during sunny days, or put them on an indoor platform during rainy period before storing them in households or granaries.
Corn kernels are processed to varieties of corn-based foods and feed besides being directly consumed as food. We conducted another survey of fumonisins contamination in corn-based food and feed samples from central markets of Lianxian County. The results showed that $\mathrm{FB}_{1}$ was detected in the ranges from 0.21 to $0.28 \mu \mathrm{g} / \mathrm{g}$ (mean, $0.25 \pm 0.04 \mu \mathrm{g} / \mathrm{g}$ ) in 7 of $39(17.9 \%)$ processed corn food samples. No fumonisin was detected in all corn flour, corn meal and corn tortilla chip samples, only one of six vaccum-packaging cooked corn cob samples detected positive $\mathrm{FB}_{1}$ at the level of $0.28 \mu \mathrm{g} / \mathrm{g}$. However, $\mathrm{FB}_{1}$ was detected at the concentration ranging from 0.21 to $0.27 \mu \mathrm{g} / \mathrm{g}$ in 6 of $12(50 \%)$ corn grit samples (Table 3). Our results showed that less or no contamination of fumonisin was found in the processed corn products, which is coincident with previous reports ([Weidenbörner, 2001] and [Humpf and Voss, 2004]). Several previous studies were conducted to investigate the effect of processing method on fumonisn content. It was reported that the use of alkaline solution, water and temperature, used in the prepared corn-based foods might contribute to variations in the occurrence of fumonisin (Soriano \& Dragacci, 2004). Cleaning corn to remove damaged or moldy kernels reduces fumonisins in foods while milling increases their concentration in some and reduces their concentration in other products (Jackson \& Jalonski, 2004). Humpf and Voss (2004) found that baking, frying, and extrusion cooking of corn at high temperatures $\left(\geq 190^{\circ} \mathrm{C}\right)$ also reduced fumonisin concentrations in foods, with the amount of reduction achieved depending on cooking time, temperature, recipe, and other factors. It was also suggested that the fumonisin level in corn-based products was reduced during processing because fumonisins become 'hidden' and not recoverable under currently used extraction/purification procedures (Kim, Scott, \& Lau, 2003). There are only a few reports on fumonisin contamination in corn-based products in China, while relatively more surveys are conducted in the occurrence of fumosins in corn-based products in some other countries (Soriano

Table 3. Fumonisin contamination of corn-based foods and feeds from central market

\begin{tabular}{|c|c|c|c|c|c|}
\hline \multirow[t]{2}{*}{ Use purpose } & \multicolumn{3}{|c|}{ Samples } & \multicolumn{2}{|c|}{$\begin{array}{l}\text { Level of } \mathrm{FB}_{1} \text { in positive } \\
\text { samples }\end{array}$} \\
\hline & \multicolumn{3}{|c|}{$\begin{array}{r}\text { Number Positive } \\
\text { (incidence) }\end{array}$} & $\begin{array}{l}\text { Mean } \\
(\mu \mathrm{g} / \mathrm{g})\end{array}$ & $\begin{array}{l}\text { Range } \\
(\mu \mathrm{g} / \mathrm{g})\end{array}$ \\
\hline Processed foc & & 39 & $7(17.9 \%)$ & $0.25 \pm 0.04$ & $0.21-0.28$ \\
\hline Corn grit & & 12 & $6(50 \%)$ & $0.23 \pm 0.03$ & $0.21-0.27$ \\
\hline Corn flour & & 6 & 0 & - & - \\
\hline Corn meal & & 9 & 0 & - & - \\
\hline Corn tortilla & hips & 6 & 0 & - & - \\
\hline $\begin{array}{r}\text { Vacuum-pack } \\
\text { cooked cor }\end{array}$ & $\begin{array}{l}\text { aging } \\
\text { a cob }\end{array}$ & 6 & 1 & 0.28 & 0.28 \\
\hline Unprocessed & food & 48 & $16(33.3 \%)$ & $0.47 \pm 0.12$ & $0.31-0.63$ \\
\hline Feed & & 28 & $15(53.6 \%)$ & $1.50 \pm 1.24$ & $0.30-3.13$ \\
\hline
\end{tabular}


and Dragacci, 2004; and Weidenbörner, 2001). Moreover, the consumption of corn is different from other countries in China as some special processing methods are used. It will be interesting to further investigate the effect and mechanism of different processing methods on fumonisin level of corn-based foods.

High levels of $\mathrm{FB}_{1}(1.50 \pm 1.24 \mu \mathrm{g} / \mathrm{g})$ were found in 15 of $28(53.6 \%)$ feed samples with the maximal level of $3.13 \mu \mathrm{g} / \mathrm{g}$, which suggests that the feed produced in Linxian County need some more suitable practice for fumonisin control. In Linxian County, the corn kernels with good visual quality and low moisture content are directly traded in the market or used to made corn-based foods, while those with relatively poor quality are stored and consumed by the farmers or used to produce feed. Our results indicated that the fumonisin contamination is more serious in corn feed than in corn-based foods obtained from central markets. The Food and Drug Administration of USA has announced guidance levels for total fumonisin levels in corn products, 2-4 ppm for human foods and 5-100 ppm for animal feeds depending on the species and the proportion of the contaminated material in the total diets (FDA, 2002). Therefore, the feed traded in central markets of Linxian County is still safe according to this guidance standard.

\section{Conclusion}

$\mathrm{FB}_{1}$ was the only fumonisin detected by HPLC-ELSD in all corn-based food and feed samples collected in Linxian County, a high-risk area for esophageal cancer in China. No fumonisin was detected in corn samples from local supermarket, and processed corn foods (corn flour, corn meal, and corn tortilla chips) from local central markets. Low average levels of $\mathrm{FB}_{1}(<2 \mu \mathrm{g} / \mathrm{g})$ were found in all corn samples collected locally, and all corn-based food and feed samples from local central markets, although relatively high levels of $\mathrm{FB}_{1}$ were detected in corn samples from local granaries, and moldy corn samples from local households with maximal $\mathrm{FB}_{1}$ level of 3.20 and $3.30 \mu \mathrm{g} / \mathrm{g}$, respectively. The results indicate that new practices should be adopted to control the fumonisin contamination of corn kernels stored in granaries and households.

\section{Acknowledgements}

This work was supported by the National Natural Science Foundation of China (30428023, 30320974), Fok Ying Tong Education Foundation (104034), NCET-05-0516, and Natural Science Foundation of Zhejiang Province (R304103).

\section{References}

Bittencourt et AL., 2005 - A.B.F. Bittencourt, C.A.F. Oliveira, P. Dilkin, and B. Corrêa, Mycotoxin occurrence in corn meal and flour traded in São Paulo, Brazil, Food Control 16 (2005), pp. 117-120.
BojJa et AL., 2004 - R.S. Bojja, R.L. Cerny, R.H. Proctor, and L.C. $\mathrm{Du}$, Determining the biosynthetic sequence in the early steps of the fumonisin pathway by use of three gene-disruption mutants of Fusarium verticillioides, Journal of Agricultural and Food Chemistry 52 (2004), pp. 2855-2860.

Chu and Li, 1994 - F.S. Chu and G.Y. Li, Simultaneous occurrence of fumonisin $\mathrm{B}_{1}$ and other mycotoxins in moldy corn collected from the People's Republic of China in regions with high incidences of esophageal cancer, Applied and Environmental Microbiology 60 (1994), pp. 847-852.

FDA, 2002 - FDA. (2002). Draft guidance for industry: fumonisin levels in human foods and animal feeds; availability. Fed.Regist, 65,35945 . Available from http://www.cfsan.fda.gov/ dms/fumongui.html.

Gelderblom et al., 2001 - W.C. Gelderblom, S. Abel, and C.M. Smuts, Fumonisin-induced hepatocarcinogenesis: mechanisms related to cancer initiation and promotion, Environmental Health Perspectives 109 (Suppl 2) (2001), pp. 291-300.

Harrison et AL., 1990 - L.R. Harrison, B.M. Colvin, J.T. Greene, L.E. Newman, and J.R. Cole, Pulmonary oedema and hydrothorax in swine produced by fumonisin $\mathrm{B}_{1}$, a toxic metabolite of Fusarium moniliforme, Journal of Veterinary Diagnostic Investigation 2 (1990), pp. 217-221.

Hendricks, 1999 - K. Hendricks, Fumonisins and neural tube defects in South Texas, Epidemiology 10 (1999), pp. 198-200.

HumpF and Voss, 2004 - H.U. Humpf and K.A. Voss, Effects of thermal food processing on the chemical structure and toxicity of fumonisin mycotoxins, Molecular Nutrition and Food Research 48 (2004), pp. 225-269.

JACKSON AND JALONSKI, 2004 - L. Jackson and J. Jalonski, Fumonisins. In: O.M. Magan, Editor, Mycotoxins in food, CRC Press, Boca Raton, Boston, New York, Washington, DC, USA (2004), pp. 380-385.

Kim et AL., 2003 - E.K. Kim, P.M. Scott, and B.P.Y. Lau, Hidden fumonisin in com flakes, Food Additives and Contaminants 20 (2) (2003), pp. 161-169.

Marasas, 2001 - W.F.O. Marasas, Discovery and occurrence of the fumonisins: A historical perspective, Environmental Health Perspectives 109 (2001), pp. 239-243.

Merrill et AL., 2001 - A.H. Merrill Jr., M.C. Sullards, K.A. Voss, and R.T. Riley, Sphingolipid metabolism: roles in signal transduction and disruption by fumonisins, Environmental Health Perspectives 109 (Suppl 2) (2001), pp. 283-289.

Nelson et Al., 1993 - P.E. Nelson, A.E. Desjardins, and R.D. Plattner, Fumonisins, mycotoxins produced by Fusarium species: Biology, chemistry, and significance, Annual Review of Phytopathology 31 (1993), pp. 233-252.

Rheeder et AL., 1992 - J.P. Rheeder, W.F.O. Marasas, P.G. Thiel, E.W. Sydenham, G.S. Shephard, and D.J. Van Schalkwyk, Fusarium moniliforme and fumonisins in corn in relation to human oesophageal cancer in Transkei, Phytopathology 82 (1992), pp. 353-357.

RHEeder ET AL., 2002 - J.P. Rheeder, W.F. Marasas, and H.F. Vismer, Production of fumonisin analogs by Fusarium species, Applied and Environmental Microbiology 68 (2002), pp. 2101-2105.

SAnchis ET AL., 1995 — V. Sanchis, M. Abadias, L. Oncins, N. Sala, I. Vinas, and R. Canela, Fumonisins $\mathrm{B}_{1}$ and $\mathrm{B}_{2}$ and toxigenic $\mathrm{Fu}$ - 
sarium strains in feeds from the Spanish market, International Journal of Food Microbiology 27 (1995), pp. 37-44.

ShePhARD ET AL., 2005 - G.S. Shephard, L. Van der Westhuizen, P.M. Gatyeni, D.R. Katerere, and W.F.O. Marasas, Do fumonisin mycotoxins occur in wheat?, Journal of Agricultural and Food Chemistry 53 (2005), pp. 9293-9296.

Soriano AND Dragacci, 2004 - J.M. Soriano and S. Dragacci, Intake, decontamination and legislation of fumonisins in foods, Food Research International 37 (2004), pp. 367-374.

Sydenham ET AL., 1990 - E.W. Sydenham, P.G. Thiel, W.F.O. Marasas, G.S. Shephard, D.J. Van Schalkwyk, and K.R. Koch, Natural occurrence of some Fusarium mycotoxins in corn from low and high esophageal cancer prevalence areas of the Transkei, Southern Africa, Journal of Agricutural and Food Chemestry 38 (1990), pp. 1900-1903.
Wang ET Al., $2000-$ H. Wang, H. Wei, J. Ma, and X. Luo, The fumonisin $\mathrm{B}_{1}$ content in corn from North China, a high-risk area of oesophageal cancer, Journal of Environmental Pathology Toxicology and Oncology 19 (2000), pp. 139-141.

WANG AND ZHu, 2002 - Y. Wang and T.X. Zhu, Determination of $\mathrm{FB}_{1}$ in corn with high incidence of esophageal cancer in Linxian Jingtoucun, Journal of China Agricultural University. 7 (1) (2002), pp. 9-13 (in Chinese).

WeIDEnBörner, 2001 - M. Weidenbörner, Foods and fumonisins, European Food Research and Technology 212 (2001), pp. 262-273.

Yoshizawa et AL., 1994 - T. Yoshizawa, A. Yamashita, and Y. Luo, Fumonisin occurrence in corn from high- and low-risk areas for human esophageal cancer in China, Applied and Environmental Microbiology 60 (1994), pp. 1626-1629. 